\title{
Editorial
}

\section{Cohobation in Spagyric or Electro Homeopathy}

\section{Debasish Kundu}

American Nutritional Medical Association, 1861 Ericson Circle, Stockton, U. S. A.

\section{Email address:}

drdkundu@hotmail.com

\section{To cite this article:}

Debasish Kundu. Cohobation in Spagyric or Electro Homeopathy. International Journal of Homeopathy \& Natural Medicines. Vol. 3, No. 3, 2017, pp. 31-34. doi: 10.11648/j.ijhnm.20170303.12

Received: November 9, 2017; Accepted: November 10, 2017; Published: December 13, 2017

\begin{abstract}
Cohobation in "Alchemy" is the assembling of the purified elements got by mean of Spagyrism. It is not concern to the act of passing again and again a solvent over a substance to open it and to dissolve it as per the definition given by Glaser's. Theodore Krauss initiated the term 'Cohobation' in Plant Alchemy. According to him it is a cold distillation process with fermentation. In this review article author traces its source and relationship with Spagyric or Electro Homeopathy.
\end{abstract}

Keywords: Cohobation, Plant Alchemy, Spagyric Homeopathy, Electro Homeopathy

\section{Introduction}

Phillipus Aureolus Theophrastus von Hohenheim (Paracelsus, 1493-1541CE), was the first to write extensively on the subject of spagyrics, in which both vital healing energy and active substances are extracted from medicinal plants, creating powerful mother tinctures. Derived from the Greek words spao (separate) and ageiro (unite), spagyric remedies were originally created by fermenting parts of wild herbs. This process produced concentrated aromatic solutions that were extracted and separated from the bulk plant materials. After fermentation is completed, the plant material is distilled in a special device, and the remainder dried and burned. The ashes are extracted and purified via distillation, then recombined with the concentrated solution. As a result, the finished spagyric essence contained the mineral constituent parts of the plant. Paracelsus pointed out that the vital energy of an herb is more important than the plant material itself. Following the footprints of Johann Baptist Van Helmont with Hahnemannian principles, Italian Alchemist Cesare Mattei (1809-1896), introduced his Spagyric Homeopathic Medicines under Brand Name 'Electro Homeopathy' and his system got official recognition from Pope Pius IX. Cesare Mattei is credited to be the father of Spagyric Homeopathy.

Various schools of Spagyric Homeopathy is recognized in GHP/USHP. Respectively, Zimpel, Krauss, Beyersdorff, Strathmeyer, Gluckselig and Bernus prescriptions are covered in GHP and Zimpel, Krauss and Beyersdorff (Pekana) prescriptions are covered in USHP. Spagyric Homeopathy medicine is also recognized in Switzerland, Australia and South Africa.

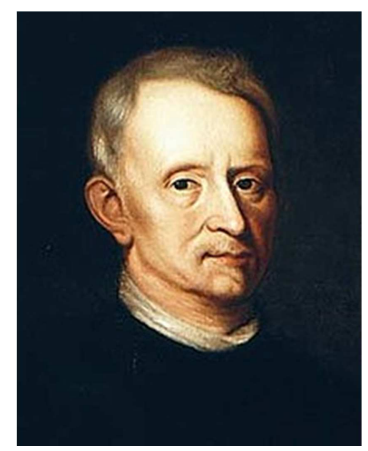

Figure 1. Johann Baptist Van Helmont.

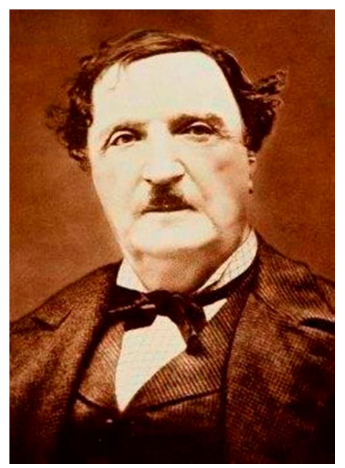

Figure 2. Cesare Mattei. 


\section{Materials and Methods}

Cesare Mattei in his Vade mecum revealed his Electrohomeopathy is Alchemy (Spagyric Medicine). In Principles of Electro Homeopathy, he wrote, "....... it is the principle called Enormou by Hippocrates, the archea, of Van Helmont,....". [1] [2]

After the death of Cesare Mattei In 1896, some so called disciples of Cesare Mattei however replicated or produced Spagyric Homeopathic medicines. Amongst them one of the key figures was Theodore Krauss of Germany (1864-1924) whose grandfather had been a pupil of Hahnemann's. In early life, Krauss practiced under the guidance of his grandfather, after his death he worked with legendary Homeopath Franz Pesendorfer (life dates unknown) in Gmunden/Austria. Krauss also intensely studied Mattei's Electro Homoeopathy. $\mathrm{He}$ favoured Cohobation, a cold distillation process with fermentation .... [3] [4]

\section{Discussion}

In plant kingdom, the spirit/Mercury is the life force or vital essence of the plants and released by all plants during the fermentation process (death). The spirit/Mercury is also the life force or vital essence of the universe and thus creates the major points of interest as according to Spiritual Alchemy. [5.1]

The soul of the plant kingdom is the essential oil which the plants possess. The soul (Sulphur) is the consciousness of three world (kingdom). The Body (Salt) of the vegetable world is what remaining after the spirit has left. It is also called caput- mortem. It is then burnt until it turns into ashes and finally turns to white salt.

In alchemy after the Cohobation the product undergoes a long Digestion at a constant temperature or a circulation. According to Von Bernus definition, the aim \& the effect of digestion is to obtain the loosening of the textures of substances to allow their opening \& dissolution. This phenomenon must be considered as identical to the one that happens in the stomach of an animal. [6]

As per Dennis William Hauck, 'Cohobation' is a distillation process after 'digestion'.

"The plant's soul (or Sulfur) is obtained by steam-distilling the essential oil from the crushed plant. The remaining parts of the plant are digested and fermented, and the resulting solution is rectified to get the alcohol or spirit of Mercury, which is its life force. The residue of stems and leaves left behind is the plant's dead body. This material is dried and incinerated to ash. The ash is ground fine, dissolved in water, and filtered. The liquid is then evaporated, which produces a fine, white crystalline Salt. This is the plant's true body. The separated Three Essentials are now recombined. First, the crystallized Salt is roasted for a week. Then the Salt is ground again and spread in a warm dish outdoors to absorb atmospheric moisture. Alternatively, a few drops of fresh dew can be added. This whole process is repeated two more times. Next, the Salt is saturated with its oily Sulfur and placed in an incubator.
After a week, the Salt is reanimated by saturation with the alcohol spirit of its Mercury. After a period of digestion, the solution is distilled by cohobation, in which the condensate is poured again and again upon the matter left at the bottom of the vessel. Finally, the original plant is resurrected in an exalted form known as the elixir." [5]

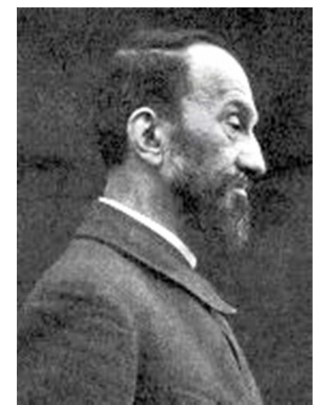

Figure 3. Theodore Krauss.

According to Bettina Blessing, Cohobation of Theodore Krauss is a cold distillation process with fermentation that retained the living, radio-active powers of the plants by accumulating or suspending them in the obtained essence. He recommended to gather the shoots, seeds, branches, leaves, blossoms, fruit, bark, bulbs or roots of the plants one needed in the spring or autumn, when the juices of the plant organism were active, extract their juices by making incisions and soak them in distilled water (maceration) at $35^{\circ} \mathrm{C}$. After that, one had to keep macerating fresh plant material, not in water, but in that solution. The solution gained more and more medicinal substance in the process until full saturation was achieved. The tincture should then be poured into big glass containers, called recipients, where it remained until it was completely clear; as a result of the fermenting process the impure substances would settle on the ground of the recipient as sludge, while the pure, clear essence contained all the medicinal properties of the plant in a refined, "virtually spiritualised" form, but without the ballast of the plant body and only bound to a small amount of water. [3.1]

According to Clare Goodrick-Clarke, to perform Cohobation, the purifled salts are placed in a huge jar and the tincture is poured over them. There will be a distinct change in the color and aroma of the mixture. The jar is to be sealed tightly, and placed in a warm, dark place and left for two weeks, then the solution is to be decanted into a dark glass bottle, which is the spagyric tincturc, "It is good medicine in its own right, but one final step will make it even better: In this next phase, which is called exaltation, sublimation, or simply circulation, the tincture is dynamized into a true essence." [7]

As per Hermetic philosophy, Cohobation (elevation) is the rejoining of distillate to its source for further distillation or co-habitation after marriage of the opposites or the three purified prima materials. Which is achieved through repeated distillations in which the distillate is repeatedly reunified with the residue, and the distillation is carried out a new. Through continual changes in the aggregate conditions of the distillate 
and through the reunification with the residue in the distillation container, the distillate attains a high level of purity and, at the same time, its effectiveness is dynamised. [8]

In the webpages of revolvy. com (as on 16 September 2017), under the topic 'Cohobation' the following is written:

"In pre-modern chemistry and alchemy, Cohobation was the process of repeated distillation of the same matter, with the liquid drawn from it; that liquid being poured again and again upon the matter left at the bottom of the vessel.[9] Cohobation is a kind of circulation, only differing from it in this, that the liquid is drawn off in cohobation, as in common distillation, and thrown back again; whereas in circulation, it rises and falls in the same vessel, without ever being drawn out. [10] [11]

Cohobation is equivalent to performing the same distillation a number of times and does not increase the purity of the distillate or alter the residue any more than would be done by maintaining it at elevated temperature for the same period of time. The Dean-Stark trap does involve returning some distillate to the reaction flask: a solution is distilled and the condensed liquid is collected in a tube wherein water settles to the bottom and is drained out, while an organic solvent returns to the boiling solution. However, the process is not manual, most of the solvent does not leave the reaction flask, and the apparatus achieves a useful purpose (removing water from the reaction mixture). Circulation, on the other hand, is approximately the same as reflux, where a solution is maintained at its boiling point by condensing the distilling vapors and returning them directly to the reaction mixture. [12]

In Biotechnology, Cohobation is a technique that can be used for water or steam distillation. It uses the process of returning the distillate water to the still after the oil has been separated from it so that it can be re-boiled. This is basically an improvised methodology of the directly fired type steam and water distillation units for oils which have partial solubility in water.

As according to Prof. Ali Talati, Biotechnologist (Aromatic and Medicinal Plants Pharmacy) Cohobation is a procedure that can only be used during water distillation or water and steam distillation. It uses the practice of returning the distillate water to the still after the oil has been separated from it so that it can be re-boiled. The principal behind it is to minimize the losses of oxygenated components, particularly phenols which dissolve to some extent in the distillate water. For most oils, this level of oil loss through solution in water is less than $0.2 \%$, whereas for phenol-rich oils the amount of oil dissolved in the distillate water is $0.2 \%-0.7 \%$. As this material is being constantly re-vaporized, condensed and re-vaporized again, any dissolved oxygenated constituents will promote hydrolysis and degradation of themselves or other oil constituents. Similarly, if an oxygenated component is constantly brought in contact with a direct heat source or side of a still, which is considerably hotter than $100^{\circ} \mathrm{C}$, then the chances of degradation are enhanced.

As a result, the practice of Cohobation is not recommended unless the temperature to which oxygenated constituents in the distillate are exposed is no higher than $100^{\circ} \mathrm{C}$.
In steam and water distillation, the plant material cannot be in direct contact with the fi re source beneath the still; however, the walls of the still are good conductors of heat so that still notes can also be obtained from the thermal degradation reactions of plant material that is touching the sides of the still. As the steam in the steam and water distillation process is wet, a major drawback of this type of distillation is that it will make the plant material quite wet. This slows down distillation as the steam has to vaporize the water to allow it to condense further up the still. One way to prevent the lower plant material resting on the grid from becoming waterlogged is to use a baffle to prevent the water from boiling too vigorously and coming in direct contact with the plant material. [13]

\section{Conclusion}

The process of reassembling the three purified principles (Salt, Sulphur, and Mercury) does not constitute Cohobation, but rather it is the feel good factor which is yielded after successful co-habitation of the three purified elements or Alchemical Marriage as per Sexual Alchemy. [5.2]

Maceration is the process of dissolving the active principles from a plant by allowing the latter to remain at room temperature in contact with the solvent (alcohol or aqua dist. or glycerine) for several days, with frequent agitation, and finally filtering. It is widely used in Homeopathic Pharmacy. In Cohobation as demonstrated by Theodore Krauss, parts of Plants are fermented (decomposed) in water, filtered and the Liquid is collected. The residue is to be processed for maceration in ethanol, finally both the aquatic and alcoholic solutions are collected and mixed. Krauss was from Homeopathic background and this process does not conform to traditional Alchemy but rather in line with Homeopathic Pharmacy.

In the works of Paracelsus, Van Helmont and other Alchemists including Cesare Mattei there is no mention of the term 'Cohobation'. Theodore Krauss is credited to be the initiator of the term Cohobation in Spagyrics or Plant Alchemy.

\section{Acknowledgements}

1. Gisela Bruckl, Adler-Apotheke, Wurzburg, Germany

2. Justin Sinclair, National Herbalists Association of Australia (NHAA)

3. Leonardo Anfolsi, Academy of Operative Alchemy/ NitroGeno, Italy

\section{References}

[1] Principles \& Art of Cure in Electro Homeopathy: Dr. Debasish Kundu (Originals, New Delhi).

[2] Mysticism, Romance \& Secrets of Count Cesare Mattei: Dr. Debasish Kundu (LBO Publishing, 700 N Valley St., Suite B PMB 11884 Anaheim, CA 92801, USA). 
[3] Pathways of Homoeopathic Medicine: Bettina Blessing, Institute for the History of Medicine, Robert Bosch Foundation, Stuttgart, Germany.

[4] Pharmacodynamics in Spagyric Medicine (Plant Alchemy): Dr. Debasish Kundu \& Dr. Sudeshna Kundu, Edited by Gisela Bruckel (Germany), El Akrem Hayouni (Tunisia), Forwarded by Peter Morrell (UK), Prof. Luigi Vernacchia, \& Dr. Fabio Ambrosi (Italy) (LBO Publishing, $700 \mathrm{~N}$ Valley St., Suite B PMB 11884 Anaheim, CA 92801, USA).

[5] Notes on Spagyrics: Dr. Debasish Kundu (Originals, New Delhi).

[6] Praxis Spagyrik: Nach Alexander von Bernus, Trias; 3., überarbeitete Auflage. Edition.

[7] Alchemical Medicine for the 21st Century: Spagyrics for Detox, Healing, and Longevity By Clare Goodrick-Clarke, Chapter 6, p. 104.

[8] Hermetic library article; "Spagyric Elixirs Pt. 3: Further Calcination and Cohobation

https://enteralchemy.wordpress.com/2014/03/14/spagyric-elixi rs-pt-3-further-calcination-and-cohobation/.

[9] "Cohobate"; "Cohobation". Oxford English Dictionary, Oxford University Press. 2nd ed. 1989.

[10] Text from a publication now in the public domain: Chambers, Ephraim, ed. (1728). "Cohobation". Cyclopædia, or an Universal Dictionary of Arts and Sciences (first ed.). James and John Knapton, et al.

[11] Text from a work in the public domain: Porter, Noah, ed. (1913).
"Cohobation". Webster's Dictionary. Springfield, Massachusetts: C. \& G. Merriam Co.

[12] A Treatise on Spagyric Homoeopathic Pharmacy By Dr. Debasish Kundu, Edited By Dr. Vijai Kant Agnihotri, Scientist, CSIR, Govt of India, Foreworded By Raffaele Pezzani, University of Padova, Italy. (Originals, New Delhi).

[13] Extraction Methods of Natural Essential Oils: Prof. Ali Talati, Shiraz University of Medical Sciences, Iran, Stem Cell and Transgenic Technology Research Center, DOI: 10.13140/RG.2.2.18744.3456402/2017.

\section{Biography}

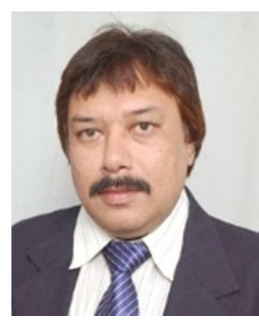

Dr. Debasish Kundu is a $\mathrm{Ph}$. D. from one American University, he is the Vice President, American Nutritional Medical Association, CA, U. S. A., and a Faculty, Association of Independent Natural Science Schools Colleges, Professions \& Arts, MO, U. S. A. He has authored more than 27 books on health and social topics, his books have been listed as recommended texts in several national and international organisations, incl., Agricultural Research, Education \& Extension Organization (AREEO), Government of Iran. Dr. Kundu is the Editor In Chief of International Journal of Homeopathy \& Natural Medicines (IJHNM). 